PNL-6783

UC-95

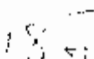

\title{
The Potential for Air Flow Reduction in Fume Hoods at Hanford
}

W. I. Enderlin

December 1988

Prepared for the U.S. Department of Energy under Contract DE-AC06-76RLO 1830

Pacific Northwest Laboratory Operated for the U.S. Department of Energy by Battelle Memorial Institute 


\section{DISCLAIMER}

This report was prepared as an account of work sponsored by an agency of the United States Government. Neither the United States Government nor any agency thereof, nor Battelle Memorial Institute, nor any or their employees, makes any warranty, expressed or implied, or assumes any legal liability or responsibility for the accuracy, completeness, or usefulness of any information, apparatus, product, or process disclosed, or represents that its use would not infringe privately owned rights. Reference herein to any specific commercial product, process, or service by trade name, trademark, manufacturer, or otherwise does not necessarily constitute or imply its endorsement, recommendation, or favoring by the United States Government or any agency thereof, or Battelle Memorial Institute. The views and opinions of authors expressed herein do not necessarily st ate or reflect those of the United States Government or any agency thereof.

\section{PACIFIC NORTHWEST LABORATORY operated by \\ BATTELLE MEMORIAL INSTITUITE \\ for the \\ UNITED STATES DEPARTMENT OF ENERGY \\ under Contract DE-AC06-76RLO 1830}

\begin{tabular}{|c|c|}
\hline \multicolumn{2}{|c|}{ Printed in the United States of America } \\
\hline \multicolumn{2}{|c|}{ Available from } \\
\hline \multicolumn{2}{|c|}{ National Technical information Service } \\
\hline \multicolumn{2}{|c|}{ United States Departmen1 of Commerce: } \\
\hline \multicolumn{2}{|c|}{5285 Port Royal Road } \\
\hline \multicolumn{2}{|c|}{ Springfield, Virginia 22161} \\
\hline \multicolumn{2}{|c|}{ NrIs Price Codes } \\
\hline \multicolumn{2}{|c|}{ Micrufiche A01 } \\
\hline \multicolumn{2}{|c|}{ Printed Copy } \\
\hline & Price \\
\hline Pages & Codes \\
\hline $001-025$ & A02 \\
\hline $026-050$ & A03 \\
\hline $051-075$ & $A 04$ \\
\hline $076-100$ & A05 \\
\hline $101-125$ & $A 06$ \\
\hline $126-150$ & $\mathrm{~A} 07$ \\
\hline $151-175$ & $A 0 A$ \\
\hline $176-200$ & $A D 9$ \\
\hline $201-225$ & A 10 \\
\hline $226 \cdot 250$ & A11 \\
\hline $251-275$ & A12 \\
\hline $276-300$ & A13 \\
\hline
\end{tabular}


PNL -6783

UC-95

THE POTENTIAL FOR AIR FLOW

REDUCTION IN FUME HOODS AT HANFORD

W. I. Enderlin

December 1988

Prepared for the U.S. Department of Energy under Contract DE-ACO6-76RLO 1830

Pacific Northwest Laboratory

Richland, Washington 99352 



\section{CONTENTS}

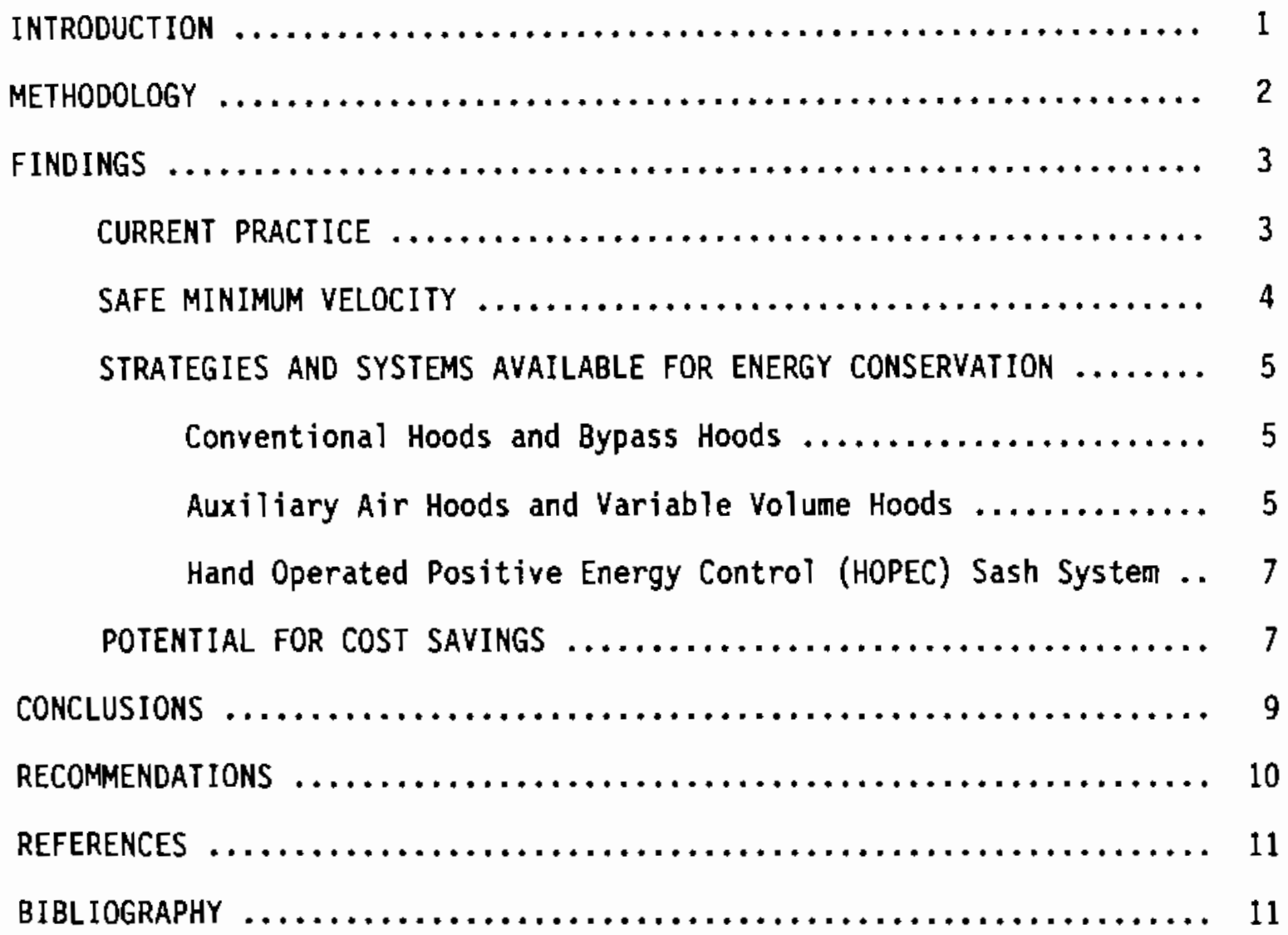





\section{THE POTENTIAL FOR AIR FLOW REDUCTION}

IN FUME HOODS AT HANFORD

\section{INTRODUCTION}

The objective of this task is to investigate the feasibility of reducing air flow at the face of laboratory hoods at Hanford during off shift hours for the purpose of energy conservation. Identifying strategies and systems currently available on the market that would facilitate such a reduction, should it be deemed feasible, is also an objective.

This report discusses the methodology employed in performing this investigation and the findings resulting therefrom and sets forth conclusions and recommendations derived from these findings. A bibliography and list of references are included 


\section{METHODOLOGY}

During the course of this investigation, a literature search was performed, the accepted standard procedure for testing the performance of laboratory fume hoods was reviewed, and experts on the subject were consulted. The information obtained was then distilled and analyzed and the findings were summarized.

A search of the open literature since 1980 was performed using the DIALOG information base. Key words used for the search were: "fume/hood", "laboratory/exhaust", "laboratory/ventilation", and "energy conservation". of the 43 citations produced, 15 were deemed applicable to this investigation and are listed in the bibliography.

Textbooks covering the fundamentals of industrial ventilation and laboratory hood design, fundamentals of pneumatic transport, and the fundamentals of industrial hygiene were reviewed to obtain relevant background information that provides a basis for the current guidelines and standard practices for the design, installation, and operation of laboratory fume hoods. This material is also referenced in the bibliography.

The standard procedure for testing fume hood performance, approved by both The American Society of Heating, Refrigerating, and Air-Conditioning Engineers (ASHRAE) and the American National Standards Institute (ANSI) was reviewed (ANSI/ASHRAE 110-1985), together with recent work of the ASHRAE standards committee for fume hoods.

The following experts in the field of industrial/laboratory ventilation were contacted:

- Dick Hubbard, Consultant, Ventilation Consultant Services, (formerly with the University of Washington), Forty-One 165th Ave. S.E., Bellevue, WA, (206) 746-9826.

- Everet Sejpp, Engineer, Lederle Lab Division of American Cyanamid Corp., Cyanaimid Plaza, Wayne, NJ, (914) 735-2373.

- Jerry Koenigsberg, Laboratory Designer, GPR Planners, 186 West Lake Shore Drive, Rockaway, NJ, (914) 997-0666. 


\section{FINDINGS}

The following summarizes the findings of this investigation with regard to current practices, safe minimum face velocity, strategies and systems available for energy conservation, and potential for cost and energy savings.

\section{CURRENT PRACTICE}

Currently, good practice dictates that the minimum face velocity for general hood use is $100 \mathrm{fpm}$ with the sash full open and $150 \mathrm{fpm}$ with the sash full open when toxic substances or carcinogenics are used in the hood. These values are reflected in the American Conference of Governmental Industrial Hygienists (ACGIH) Manual of Recomended Practice for Industrial Ventilation (ACGIH, 1984). The basis for these values is found in Occupational Safety and Health Administration (OSHA) Standard, Part 1910.93 (June 1974), Subpart $G$. The face velocity is determined by taking air velocity readings with a calibrated anemoneter at each equally spaced intersection of an imaginary grid pattern in the face of the hood and averaging the readings. There must be one grid intersection for each square foot of face area (ANSI/AHRAE 110-1985, Sec. 6.3). It must be understood, however, that capture velocity depends on total air flow entering the hood. High face velocity is not the important factor. The capture of contaminants depends on mass a ir movement, not mere face velocity (W.G. Hazard, 1971). Good practice also dictates that the minimum amount of air handled by the hood should be 60$100 \mathrm{cfm}$ for each square foot of opening at the face (ACGIH, 1984).

However, the drive for high fume hood efficiency, attained through high face velocity, is placed on a direct collision course with the need for energy conservation. As a result, Knudson and Caplan conducted a research project wherein they were able to define true hood efficiency and designed a procedure which allowed them to quantify it. The results of their studies showed that there is no correlation of hood velocity, between 60 and 125 fpin, with hood performance and hence arbitrary face velocities may or may not be appropriate for a specific hood in a specific room with a room air supply system already in place (Koenigsberg, 1984).

Ultimately, the test procedure developed by Knudson and Caplan provided the bas is for ASHRAE Standard 110 - 1985, Method of Testing Performance of Laboratory Fume Hoods. This procedure prescribes how flow in hoods should be measured but it does not prescribe the minimum allowable face velocity or flow rate. The performance test gives a relative and quantitative determination of the efficiency of the hood capture under a set of strict, although arbitrary, conditions. The performance test does not constitute an engineering investigation of what the causes may be for poor performance or of ways to improve performance (performance being the level of control of a tracer gas, in ppm, given the release rate of the gas within the hood, in Lpm). The test may be used as an aid to such an investigation. It 
remains, however, for the user of the hood to specify the level of hood performance desired/required.

\section{SAFE MINIMUM FACE VELOCITY}

There is currently very little evidence that a hood can operate safely at a face velocity of less than $100 \mathrm{fpm}$. The absolute minimum safe face velocity must be determined by testing on a case by case basis, as it is dependant on hood design, the environment and activity adjacent to the hood (including the number of people working in front of the hood), the work habits of the operator, the threshold limit values (TLV) for the materials used in the hood and the physical properties of these materials, and the type of operation conducted within the hood. Based on data contained in ORNL/TM-6400, Minimum Acceptable Face Velocities of Laboratory Fume Hoods and Guidelines for Their Classification, the industrial hygienists at Oak Ridge National Laboratory (ORNL) are of the opinion that $100 \mathrm{fpm}$ at a 40\% sash opening is the minimum acceptable face velocity for laboratory hoods and that certain operations will require greater face velocities.

Prior to 1977, the only tests available to estimate the performance of laboratory hoods were qualitative in nature, namely face velocity measurement, smoke testing, and air flow (static pressure or pitot tube) measurements. Since the late 1970s, several investigators have described sensitive quantitative tests that can and have been applied to the measurement of laboratory hood performance. Although quantitative techniques are currently available for determining minimum safe face velocity, they are not commonly used by operators because of the cost, time, and skill required to perform the tests (a). Moreover, in many cases, the data obtained has been misapplied or misinterpreted, resulting in unsafe hood operation (Koenigsberg and Seipp, 1988). As a result, most operators tend to adhere to the values set forth in the OSHA standard and the ACGIH Manual of Recommended Practice for Industrial Ventilation.

Maintaining face velocity in the range of 100-150 fpm, however, does not assure safe hood operation. In face velocity tests for handling tritium in hoods, which were performed at Mound Laboratory, using liquid nitrogen as a surrogate, spillage from the face of the hood into the room was noted at all velocities from $75 \mathrm{fpm}$ to $200 \mathrm{fpm}$ in older hoods not equipped with air foils at the hood face. In tests using helium as a surrogate for tritium, full containment was attained at $175 \mathrm{fpm}$ only when air foils were employed at the face and air balance was established between the room and the hood. It should be noted here that tritium is about as light as helium, flammable ( $L E L=3.9 \%$ to $75 \%$ ), and radioactive. Based on the results of these tests,

(a)Fairchild,0. 1984-85. Laboratory Hood Survey; Los Alamos National Laboratory; DOE Contract No. W-7405-ENG-36, 16 p. 
Mound set $200 \mathrm{fpm}$ as the minimum face velocity when working with tritium(a). However, it is very difficult to operate at high face velocities (in excess of $150 \mathrm{fpm}$ ) as they result in turbulence within the hood which tends to draw contaminants toward the face of the hood, especially when the operator is standing in front of the hood. High face velocity also causes room ventilation problems and results in enormous energy consumption for both conditioning and moving the air.

\section{STRATEGIES AND SYSTEMS AVAILABLE FOR ENERGY CONSERVATION}

There are essentially four types of hood operation systems: conventional hoods, bypass hoods, auxiliary air hoods, and variable volume (VAV) hoods. The following is a discussion of each of these systems with respect to the potential for energy conservation.

Conventional Hoods and Bypass Hoods

Conventional (constant volume) hoods and bypass hoods have been in use since early in this century. As the sash is closed on a conventional hood, the volume of air exhausted does not change; hence, high inlet velocities and loud air noise is developed when the sash is set at less than full open. The bypass hood was subsequently developed to overcome these shortcomings and was the state-of-the-art 10 to 15 years ago. As the sash is closed on a bypass hood, air is exhausted from a grille in top of the hood which is uncovered by the closing sash, thus air was "bypassed" from going through the hood. Hence, both of these hood systems are considered to have a constant high energy consumption where heating and cooling energy is exhausted and not recovered.

\section{Auxiliary Air Hoods and Variable Volume Hoods}

These two hood operation systems attracted attention after 1973. Auxiliary air hoods are actually bypass hoods that have been modified, and variable volume hoods are modified conventional hoods.

Auxiliary Air Hoods. Auxiliary air hoods have an auxiliary dedicated air system supplying air to the hoods. This auxiliary air system utilizes about $1 / 3$ to $2 / 3$ of the hood exhaust air being supplied from the auxiliary air plenum with the remainder from the room. Hence, air tempering is necessary for successful operation. However, the need for tempering defeats the major attraction of the auxiliary system (reduced energy consumption).

(a)Ross, W.O., et a]. October 1986. "Tritium Fume Hood Air Flow Analysis." Prepared by Monsanto Research Corporation for DOE, $19 p$. 
Moreover, because a separate dedicated supply air system is required for auxiliary hoods, they have a high first cost and the added system increases the complexities and maintenance costs of the system, especially the controls.

Variable Volume (VAV) Hoods. Variable volume hoods sense sash position directly or changes of pressure within the hood resulting from the sash position. This type of hood varies the quantity of air flowing through the hood, depending on sash position, so that the velocity through the open sash area is a constant (normally 100-150 fpm). Consequently, the need to condition air that simply bypassed the hood and is discharged to the atmosphere is eliminated. In addition, the sensing device in the hood controls the amount of air being pumped into the room through the central air supply system, guaranteeing constant room pressure and thus achieving air balance between the room and the hood. Usually, the hood is set up with a stop so that the sash does not fully close and the fan exhausts a minimum quantity of air at all times. The hood may also be equipped with a monitoring system that will provide an alarm when a sash is open for an extended period of time. Variable flow is nomally accomplished by varying a damper setting in the hood exhaust duct or by a variable speed motor drive on the exhaust fan, or both.

There are, however, disadvantages with the VAV concept. There is a possibility of contamination buildup on the damper in the duct. Variable speed drives are expensive to install and have a significant maintenance cost. Moreover, this system has a low exhaust air velocity when the hood sash is closed, causing the effluent to "spill" from the outside exhaust duct and possibly be picked up by outside fresh air intakes. Also, under these low flow conditions, condensation of corrosive material collects in the exhaust ducts thus reducing their useful life significantly. Good design practice requires that the minimum velocity in the exhaust duct be $2,000 \mathrm{fpm}$. A system to overcome this shortcoming has been developed utilizing large volume, low pressure fans that mix outside air with the fume hood exhaust air and discharges the mixture with adequate velocity so that the mixture is directed away from the building. Hence, the system is variable volume from the space with constant exhaust volume to the atmosphere, downstream of the fan (Albern, et al., 1988).

This system does realize the savings of not having to condition the air, but it does have the cost of operation of the large low pressure fans. The system also benefits from the energy savings of variable speed drives when they are employed. However, the equipment costs and the design and engineering costs required to incorporate this system into an existing facility could be extensive, resulting in an unacceptable return on investment (ROI). Also, any energy savings using this system will result only through strict management control over hood operation (requiring the operator to keep the hood closed as much as possible), and not strictly through mechanical means. 
According to $\mathrm{Mr}$. Koenigsberg, there are essentially four principal vendors currently in the business of selling VAV hood control systems. These vendors are:

- Environmental Control Technology, Inc., a subsidiary of TSI Inc., Bristo1, CT

- Anemostat Division, Dynamics Corp. of America, Scranton, PA

- Phoenix Controls Corp., Newton, MA

- Flow Safe Corp., Danville, NJ

Honeywell has also developed a VAV system, but it is now considered by Mr. Koenigsberg to be outdated technology. He said that each of these vendors takes a completely different approach to hood control; hence, once you have committed to a system, you are locked into a sole source for that systen.

\section{Hand Operated Positive Energy Control (HOPEC) Sash System}

In their paper, Koenigsberg and Schaal claim that major savings in energy consumption as well as dranatic increases in hood efficiency can be realized by retrofitting existing hoods or purchasing new hoods with HOPEC sash systems without changing ductwork or fans (Koenigsberg and Schaal, Oct. 1987). The HOPEC concept is based on the idea that since a hood sash is rarely used in the full open position, it makes no sense to establish a total exhaust requirement for the level at which the sash is fully open. The idea behind the KOPEC system is to reduce energy consumption by 50\% by establishing a sash limit condition whereby only half the sash opening is exposed at any one time and thus only half the air is required to exhaust the hood. This does not preclude full access to the whole chamber when necessary. HOPEC can be used with either vertical or horizontal sashes. The horizontal model permits operator access to the entire chamber without the need to remove the windows, as would nomally be required with this type of sash. Instead, all obstructions can be removed by simply raising the sash. The HOPEC system works in conjunction with a combination of low flow and sash lock alarm, which alerts the operator to even a partial loss of exhaust capacity, or if the sash is raised higher than its stop point for more than 30 seconds. Inadvertent opening of the hood is thus minimized, resulting in greater efficiency and reduced energy consumption. It should also be recognized here that the vertical sash will provide an additional safety benefit over the traditional horizontal sash if the operator will use it as a shield during hood operations.

\section{POTENTIAL FOR COST SAVINGS}

It has been estimated that the average cost to operate a fume hood at 100 fpm, with the sash full open, is over \$2,000 per hood per year, based on 1988 dollars (Albern, et al, March 1988). If the exhaust rate is increased to $150 \mathrm{fpm}$, the operating cost will increase to approximately $\$ 3,000$ per 
hood per year (Koenigsberg, October 1984). It follows then that installa$t$ ion of the HOPEC system should result in savings of at least $\$ 1,000$ to $\$ 1,500$ per hood per year for hoods operating at 100 to $150 \mathrm{fpm}$, since, as shown previously, energy consumption is reduced by 50\%. The cost per hood to install the HOPEC system is about $\$ 400$ dollars for labor and materials, based on 1987 dollars (Koenigsberg and Schaal, October 1987).

Vendors of VAV systems, claim a one to two year payback. However, the experts contacted in the course of this study feel that the ROI for VAV systems and auxiliary air systems is questionable given current energy costs. Moreover, they claim that the reliability of hardware is low and the maintenance costs are high. Mr. Koenigsberg said that he was aware of a job where 100 air flow sensors were recently installed by a VAV hood control systems contractor and over 75\% of them failed. He further stated that because the reliability of this type of system is typically low, many companies that employ VAV systems negotiate a maintenance contract and that the cost of such a contract can run about $\$ 25,000$ per year. $\mathrm{Mr}$. Koenigsberg said that he did not feel the problem with this type of system was in the concept, but rather in the poor quality of the hardware used and poor installation practices.

Mr.Koenigsberg, however, feels that the HOPEC system affords an attractive ROI, especially when used in conjunction with a two speed fan and night setback when the hood is in the non-operating mode. The cost effectiveness of the HOPEC system is well documented in a paper by Koenigsberg and Schaal (Koenigsberg and Schaal, October 1987). 


\section{CONCLUSIONS}

Based on the foregoing discussion, the following is concluded:

1. There is currently no assurance that a laboratory fume hood can be operated safely at a face velocity of less than $100 \mathrm{fpm}$ in either the operational or non-operational mode.

2. To date, there is no basis for establishing a uniform minimum face velocity for hood operations at Hanford. Moreover, this investigation has surfaced strong evidence suggesting that a minimum safe face velocity must be established for each hood operation.

3. The feasibility of reducing face velocity cannot be determined without further investigation, and it must be determined on a case-by-case basis.

4. Technology for reducing the energy consumption of laboratory fume hoods is currently available; however, the cost effectiveness of applying this technology at Hanford needs to be determined.

5. The HOPEC system used in conjunction with a two speed fan and night setback appears to be the concept that holds the most promise for cost effectively reducing energy consumption by laboratory hoods at Hanford during non-operating periods, especially in the case of conventional type hoods. Bypass hoods and auxiliary air hoods may require modification in addition to the installation of the HOPEC system. 


\section{RECOMMENDATIONS}

Based on the foregoing conclusions, the following course of action is recommended:

1. Evaluate the hood design and installation design and adjacent environment at each hood operation.

2. Determine the energy consumption for each hood operation in both the operating and standby mode.

3. Evaluate each hood operation, determining the operating schedule, types of materials used in the hood, the TLV for these materials, and the pertinent physical properties of these materials (density, physical state, LEL, flash point, etc.).

4. Determine the minimum safe mass flow rate of air required for safe hood operation in both the active and inactive modes, based on the data obtained in step 3, above.

5. Perform flow tests on the hood system as installed using ASHRAE 110. It may be necessary to develop supplemental procedures or modify ASHRAE 110, since ASHRAE 110 gives a relative and quantitative determination of the efficiency of the hood capture under a set of strict, although arbitrary, conditions.

6. Based on the results of the flow test, detemine what, if any, modifications are required to the hood, hood installation, or hood operation to facilitate a reduction in energy consumption. Consider both VAV systems and the HOPEC system.

7. Perform a cost-benefit analysis of each course of action considered in step 6 , above, including doing nothing, and identify the most cost effective solution for that specific operation.

8. Perform a study on one to three hood types employing the most cost effective set of measures identified in step 7, above, to assess the viability of this approach. 


\section{REFERENCES}

ACGIH. 1984. Industrial Ventilation: A Manual of Recommended Practice. 18 th ed.

Albern, W.F., F. Darling, L.R. Farmer. March 1988. "Laboratory Fume Hood operation," ASHRAE Jour., pp. 26-30.

ANSI/ASHRAE 110-1985. Method of Testing Performance of Laboratory Fume Hoods, The American Society of Heating, Refrigerating, and AirConditioning Engineers, Inc., $12 \mathrm{p}$.

Hazard, H.G. 1971. "Industrial Ventilation." Chapter 14 in Fundamentals of Industrial Hygiene, eds. J.B. Olishifski and F.E. McElroy, Pp. 507-45, National Safety Counci1, Chicago, Illinois.

Koenigsberg, J. and H. Schaal. October 1987. "Upgrading Existing Fume Hood Installations." Heating/Piping/Air Conditioning, pp. 77-82.

Koenigsberg, J. October 1984. "The Laboratory Fume Hood: Efficiency and Energy Conservation." Reprinted from American Laboratory, 5 p.

Koenigsberg, J. and E.H. Seipp. February 1988. "Laboratory Fume Hood." ASHRAE J., PP. 43-46.

0ak Ridge National Laboratory (ORNL). June 1978. Minimum Acceptable Face Velocjties of Laboratory Fume Hoods and Guidel ines for Their Classification. ORNL/TM-6400, Health Division, 32 p.

Occupational Safety and Health Standard, Part 1910.93, Subpart G. June 27. 1974. "Occupational Health and Environmental Control." Federal Register, 39(125) Part II. 


\section{BIBLIOGRAPHY}

Abou-Zeid, P.M. September 1986. "Lab Air Control Takes Energy Waste Out of Hood Exhaust," Research \& Development, pp. 102-3.

ASHRAE Handbook. 1987. 1987 HVAC Systems and Applications--Laboratory Fume Hoods, pp. 30.9-30.11.

Caplan, K.J. and G.W. Knudson. 1978. "Laboratory Fume Hoods: A Performance Test," ASHRAE Transactions, 84(1).

Caplan, K.J. and G.W. Knudson. October 1982. "A Performance Test for Laboratory Fume Hoods," Am. Ind. Hyg. Assoc. J., (43)722-37.

Goodfellow, H.D. 1987. "Hood Design for Ventilation Systems", Heating/Piping/ Air Conditioning, pp. 60-67.

Hughes, D. and B. McIntosh. 1982. "The Reduction of Fume Cupboard Running Costs." In Short Communication, Ann. Occup. Hyg., 25(1) 101-104.

Koenigsberg, J. 1982. "Fume Hood Design and Operations." Am. Lab. $14(8) 42$.

Oak Ridge National Laboratory (DRNL). January 1981. Proceedings of the Energy Conservation in Design for UCC-ND Managers and Specialists. CONF$8003114,481 \mathrm{p}$.

Saunders, G.T. August 1983. "HESCA Program Aids Choice of Fume Hoods by Simulating Conditions." Industrial Research \& Development, pp, 104-106.

Texas Industrial Conmission. 1981. Industrial Energy Conservation Jechnology. CONF-8104102, Vol. 2, $391 \mathrm{p}$. 


\section{DISTRIBUTION}

No. of

Copies

OFFSITE

10 DOE/Office of Scientific and

Technical Information

ONSITE

DOE Richland Operations office

1 William white

1 Don Segna

23 Pacific Northwest Laboratory

W. I. Enderlin (1)

S. A. Weakley (15)

G. B. Parker (1)

Technical Report Files (5)

Publishing Coordination (1) 


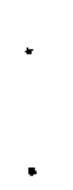

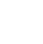

